\title{
Aspek Olah Vokal Musik Klasik Barat pada Musik Populer
}

\section{JOURNAL}

OF URBAN SOCIETY'S ARTS

Volume 1 Nomor 1 , April 2014: 44-56
A. Gathut Bintarto

Jurusan Musik, Fakultas Seni Pertunjukan, Institut Seni Indonesia Yogyakarta

Jln. Parangtritis km 6,5 Sewon, Bantul, Yogyakarta 55001

Tlp. (0274) 375380, E-mail: bintarto_853@yahoo.com

\begin{abstract}
ABSTRAK
Setiap medium musik mempunyai keistimewaan yang bisa dikaji seperti halnya pada musik klasik Barat dan musik populer. Norma daya tarik musik populer yang ringan dan mudah dinikmati tidak seperti pada musik klasik Barat atau yang sering disebut sebagai musik seni, namun demikian bukan berarti bahwa memainkannya tidak ada syarat artistik. Bervariasinya musik dan banyaknya pelaku musik mengakibatkan standar yang tinggi dan menuntut pemahaman terhadap detail musik. Musik populer bertolak dari kebiasaan orang dan musisinya ingin memenuhi kebutuhan tersebut. Gambaran emosional yang muncul pada teks menyebabkan kecenderungan naturalistik dalam bernyanyi. Melalui penelusuran asal-usul musik populer dan penelitian studi kasus di lapangan ditemukan bahwa musik populer beraliran soul serta R\&B (rhythm and blues) mempunyai kesamaan unsur dengan teknik dan gaya bernyanyi klasik pada penerapan suara yang rata dalam rentang ambitus (even scale technique), penggunaan imajinasi dengan irama bebas, nada-nada hiasan, teknik vibrato, dan bahkan gaya bernyanyi Gregorian murni dengan iringan ritmis yang dianggap sebagai suatu kebaruan dalam musik populer.
\end{abstract}

Kata kunci: olah vokal, musik klasik Barat, musik populer

\begin{abstract}
The Overview on the Aspect of Western Classical Singing on Popular Music. Every music medium such as Western classical and popular music has its own practical specification due to the observation of each characteristic and uniqueness. The potential attractiveness of popular music is different from the Western classical music in its easy listening characteristics, but it does not mean that the music does not have the artistic character at all. More performers and more variations in the popular music may affect the higher standard and require the demand in every aspect of the details. The popular music is derived from the daily habit and that is the way the musician should do to make this kind of music. The emotional characteristics in their lyrics cause the naturalistic singing tendency. Through the observation of the popular music origin and the field research study, it is founded that soul and R\& $B$ music have the similarities. In terms of the classical music, both use the typical scale technique, imagination with the free rhythm, ornamentation, vibrato technique and even pure Gregorian singing style used in some popular songs accompanied by rhythmical music served as a new idea in popular music.
\end{abstract}

Keywords: vocal technique, Western classical music, popular music 


\section{Pendahuluan}

Dalam suatu proses pembelajaran musik, setiap medium musik mempunyai keistimewaankeistimewaan yang penting untuk dikaji dalam rangka proses pengolahan untuk menghasilkan jenis karya musik tertentu, demikian pula halnya dengan instrumen musik vokal. Kegiatan berolah vokal yang lazimnya disebut sebagai seni suara atau menyanyi, menurut Shadily (1984:3384) merupakan suatu media untuk mengekspresikan keindahan musikal.

Kegiatan tersebut telah memainkan peran penting dalam setiap budaya masyarakat dan pada setiap masa. Ide dasar pengembangan kegiatannya telah didefinisikan secara lebih tegas oleh Jender dalam Sadie (1980: 338) sebagai berikut:

"Singing is a fundamental mode of expression, and better suited than dancing (in Western culture at least) to the expression of specific ideas, since it is almost always linked to a text. Even without words, however, the voice is capable of emotional utterance as unique, personal and identifiable as the cry of an infant to its mother".

Pemahaman terhadap keistimewaan bunyi vokal, sejak manusia itu dilahirkan telah mulai menjadi fokus perhatian utama dan lebih meningkat lagi, ketika seseorang mulai belajar menyanyi secara terstruktur melalui bantuan seorang guru atau pembimbing yang telah lebih dahulu mendalami masalah tersebut.

Secara umum, banyak orang menganggap bahwa menyanyi adalah suatu bakat alam yang tidak memerlukan suatu pelatihan tertentu. Pendapat ini menurut pandangan Falkner (1994: 11), hanya berlaku bagi orang-orang yang ingin menyanyi untuk kepentingan acara pertandingan olahraga sebagai supporter

Sebagai suatu instrumen musik, olah vokal melalui optimalisasi organ-organ produksi suara seperti pita suara dan rongga resonansi serta pengaturan napas telah disadari sejak era Barok. Ribeiro (1981: 177) menegaskan hal tersebut dalam pernyataannya sebagai berikut:

"Baroque singers worked on their voices as pure instruments for years and years. As a result they were able to sing phrases of disproportionate length, apparently without taking a second breath, and they could indulge in messa di voce, trills, arpeggios, turns, and rapid runs up and down the scale without becoming vocally tired.

Untuk mencapai kualitas produksi suara yang optimal dalam kegiatan menyanyi perlu dilakukan suatu kegiatan yang terstruktur dan mengarah pada pencapaian tujuan tersebut. Di samping itu, minat seseorang terhadap suatu jenis musik tertentu dan upaya-upaya yang dilakukannya dalam memahami karakter musik tersebut melalui kegiatankegiatan yang bersifat apresiatif ikut menentukan optimalisasi dalam pencapaian kualitas tersebut.

Terkait dengan praktik musikal secara umum, Sumaryo (1978: 88) menandaskan bahwa normanorma daya tarik musikal yang diterapkan pada musik populer tidak perlu sama dengan normanorma musikal yang tinggi yang dibutuhkan dalam mengolah dan mengapresiasi musik seni (art music). Namun, tidak juga berarti bahwa untuk memainkan musik populer syarat-syarat artistik tidak ada. Malahan pada waktu belakangan ini musik populer banyak yang ditujukan ke arah kegiatan artistik yang tidak terbayangkan sebelumnya. Salah satu kegiatan artistik paling menonjol dalam penggarapan musik populer adalah penyesuaian karakter vokal penyanyi dengan berbagai jenis musik yang ditawarkan untuk memunculkan nuansa musik yang 'baru'. Hal ini dilakukan selain sebagai sarana promosi juga untuk memperkenalkan ciri khas musik sebagai suatu nilai jual bagi para artis pendatang baru.

Suara Norah Jones yang disebut sebagai sultry - hangat dan menggairahkan - itu menawarkan kenyamanan berbeda di tengah musik dunia yang dimeriahkan oleh penyanyi generasi MTV semisal Britney Spears sampai Pink yang bermain di jalur pop. Musik Norah Jones merupakan ramuan musik jazz, country, blues, dan folk (Kompas, 18 Januari 2004: 1\&11).

Dengan bervariasinya jenis musik yang dikembangkan pada saat ini, perlu dikembangkan pemikiran untuk menerapkan berbagai aspek olah vokal yang telah dikembangkan oleh musik klasik Barat secara sistematis pada jenis musik 
populer. Kompleksitas pembelajaran teknik olah vokal musik klasik Barat memungkinkan untuk merumuskan suatu pendekatan yang lebih tepat dan proporsional dalam olah vokal jenis musik populer. Di samping itu, diharapkan munculnya suatu pemahaman baru bagi para penyanyi dalam mengaplikasikan instrumen musiknya pada musik populer. Hal itu sebagai bagian dari upayanya meningkatkan apresiasi terhadap berbagai jenis musik yang lain.

Pendekatan yang dilakukan dalam memahami fenomena musik populer ini kemudian tidak bertujuan agar musik ini memiliki kriteria yang sangat spesifik. Bukan pula menjadikannya sebagai sebuah seni musik yang otonom atau berdiri sendiri dengan segala bentuk aktivitas kreatif dan kebaruan yang muncul dari perilaku para artisnya. Pemahaman terhadap detail-detail musiknya bukan berarti menjadi suatu yang dapat dibakukan dan dapat berlaku umum untuk semua jenis musik yang dianggap 'populer' pada setiap masyarakat di berbagai belahan dunia. Tidak berarti pula bahwa penanganan dan pengolahan musik ini memerlukan metode pembelajaran yang perlu konsentrasi penuh seperti pada musik klasik Barat. Namun, dengan pendekatan-pendekatan umum dan pemahaman terhadap detail musiknya ditinjau dari pendekatan aspek olah vokal musik klasik Barat dapat ditunjukkan fakta-fakta objektif mengenai karakteristik kualitas musiknya. Di samping itu, dapat ditemukan aspek-aspek olah vokal musik klasik Barat yang dapat menunjang kualitas ekspresi musik populer tanpa perlu saling memengaruhi keunikan kualitas dari masing-masing musik. Dengan demikian, pendekatan terhadap penerapan olah vokal musik klasik Barat pada musik populer ini akan ditinjau secara kasus per kasus berdasarkan fakta perkembangan kedua jenis musik. Penelusuran kemungkinan penerapannya dilakukan dengan meninjau unsur-unsur yang dibutuhkan oleh musik populer dari musik klasik Barat maupun unsur-unsur yang dapat diterapkan dari musik klasik Barat pada musik populer.

\section{Pendekatan Definitif Musik Populer}

Istilah popular, menurut Dieter Mack (1995:
16) berasal dari Bahasa Latin yang berkait-an erat dengan kesan "berhubungan dengan masyarakat atau rakyat". Istilah yang merupakan kata sifat tersebut dipakai untuk menjelaskan segala sesuatu yang diketahui kebanyakan orang dan mudah dipahami rakyat. Dalam hal ini bisa dikatakan sesuatu yang populer sebaiknya atau tidak seharusnya berkaitan dengan tujuan kualitatif, melainkan dengan aspek kuantitatif. Pada setiap bidang kajian selalu terdapat semacam "aturan alami" bahwa: semakin sederhana, semakin mudah dipahami, dengan catatan kesederhanaan tersebut menyangkut kebiasaan-kebiasaan umum.

Jika istilah populer tersebut dikaitkan dengan kata musik, terdapat beberapa konotasi mendasar yang dapat mengarahkan dan menjelaskan karakteristik jenis musik tersebut secara lebih spesifik. Kenyataan yang pertama menunjukkan bahwa secara umum setiap suku, etnik, bangsa, negara mempunyai musik yang bisa ditafsirkan sebagai 'musik populer' dalam arti yang paling umum. Sebagai contoh di negara asal kata 'musik populer', yaitu di negara Barat, merupakan istilah (dengan arti tertentu) dalam bidang musik yang perkembangan makna dari istilah ini tidak bisa dilihat tanpa berhubungan dengan perkembangan media massa elektronik, seperti rekaman, piringan hitam, kaset, dan CD. Lebih konkret lagi dapat dijelaskan melalui contoh posisi lagu kebangsaan 'Indonesia Raya' yang sangat 'populer'. Dalam arti diketahui seluruh bangsa Indonesia sebagai lagu kebangsaan. Namun, lagu ini tidak bisa begitu saja ditafsirkan sebagai 'musik populer' karena fungsinya sebagai lagu kebangsaan membuatnya memiliki konotasi keagungan yang perlu mendapatkan penilaian lebih, khususnya bagi bangsa Indonesia karena nilai historis dan politis yang terkandung di dalamnya.

Seorang antropolog James Danandjaya menjelaskan bahwa folklor memiliki karakteristik sebagai musik populer karena sifat terkenalnya dalam lingkungan etnis tertentu. Kenyataan perkembangan musik folklor tertentu seperti musik 'blues' yang merupakan musik kaum kulit hitam di Amerika menjadi sulit ditentukan sebagai musik folklor ketika ia menjadi suatu seni pertunjukan yang lebih otonom. Dalam hal ini dengan munculnya penyanyi yang mempunyai keahlian khusus me- 
nyanyikan musik 'blues' tersebut. Namun, masih terdapat beberapa karakteristik lain yang perlu mendapatkan pertimbangan seperti tradisi penyebarannya yang bersifat lisan, kegunaannya yang terbatas dalam lingkungan kolektif tertentu.

Pendekatan yang lebih spesifik terhadap musik populer muncul ketika musik-musik yang berkembang di Amerika pada sekitar tahun 1950an dan 1960-an didukung oleh perkembangan media massa yang membuatnya berbeda dari aliran musik rakyat (folk music) yang ada pada waktu itu. Istilah 'musik populer', berhubungan dengan media massa, dan mau tidak mau berhubungan dengan unsur kuantitatif dari segi keuntungan uang. Ternyata inilah sebenarnya pengertian 'musik populer' yang lebih tepat pada masa kini. Musik rakyat atau folklor memang tetap berada di seluruh dunia dan di Barat juga masih dapat ditemukan, namun musik demikian tidak bersifat musik massa dalam arti komersial walaupun kadang-kadang juga sudah "di-massa-kan" (Mack, 1995:18).

Dalam suatu kutipan yang diambil dari Ensiklopedi Musik Rock, Dieter Mack memaparkan karakteristik musik populer secara lebih terinci dari segi syair dan struktur gramatika musiknya. Istilah 'popular music' di situ adalah musik yang berasal dari Amerika, yaitu semacam 'music entertaining' seperti diwakili oleh Frank Sinatra dalam kurun waktu yang cukup lama. Karakteristik musik ini digambarkan melalui tiga unsur, yaitu (1) bahasa (teks) dengan gambaran yang kuat secara emosional; (2) frase-frase melodis yang mudah dipahami (di-sekuens-kan terus-menerus); (3) instrumentasi yang bombastis dengan alat gesek dan paduan suara sebagai latar belakang.

Ketiga elemen tersebut merupakan ciri khas jenis musik "emosional" yang dalam hal ini dapat nampak dalam lagu seperti "Strangers in The Night". Karakteristik dalam lagu tersebut berbeda dengan karakteristik musik rock meskipun keduanya merupakan jenis lagu populer. Hal tersebut disebabkan dalam segi-segi tertentu seperti aspek sikap, gaya, dan juga kalangan yang menikmatinya berbeda.

Dalam tulisannya Amir Pasaribu (1997: 211) menggunakan kata hiburan menurut bahasa aslinya, yaitu entertainment. Pada waktu itu, di Indonesia pun dipakai kata crooner dan bukan singer untuk menyebut mereka yang menyanyi hiburan. Konon, pengertian singer adalah penyanyi yang menyanyi dengan voice, sedangkan crooner adalah penyanyi yang menyanyi dengan noise.

Sebuah kenyataan lain menunjukkan bahwa musik klasik karena penyederhanaan dan penggarapannya yang juga menggunakan aspek-aspek komersial dapat pula menjadi musik populer dan bersifat menghibur. Begitu pula sebaliknya, musik hiburan yang masuk dalam kategori musik populer bisa dibuat dengan keterampilan yang tinggi dan unik sehingga unsur kualitas bisa saja dimunculkan.

It might be easily inferred, for instance, that William Mann writing in The Times of London about The Beatles and their use of 'Pandiatonic Clusters' was hoping for personal pop status, or was trying to make pop respectable for 'classical musicians'. Similarly, when Tony Palmer called the same group the greatest song writers since Schubert, he sounded as if he were trying himself to elevate them to classical status. Each is misleading. The production of pop music is along quite different lines from those pursued by Western composers in the past. (Bowen dalam Spence\& Swayne, 1981:319)

Dengan demikian, masih tetap harus dipertimbangkan berbagai aspek lain, yaitu proses persepsi yang berbeda dari musik populer. Dalam hal ini perlu diingat bahwa pada prinsipnya musik populer bertolak dari kebiasaan orang, bahkan para musisinya ingin memenuhi kebutuhan banyak orang. Dengan demikian, musik ini tidak boleh membebani imajinasi musikal mereka karena harus mendengar nuansa musikal di luar kebiasaan mereka. Di samping itu, masih terdapat sejumlah permasalahan lain sejauh mana musik itu berperan. Termasuk dengan 'life style' dan fungsi idola seorang musisi pop yang menyajikan musik tersebut.

Kenyataan yang baru menunjukkan bahwa terkait dengan perkembangan teknologi, penggarapan rekaman musik pop saat ini telah melibatkan berbagai pemain musik dari pemain sitar atau shakuhachi hingga pemain orkestra. Hal ini menunjukkan bahwa pada taraf ini musik populer telah menuntut aktivitas kreatif yang meliputi berbagai kategori baik penggarapan komposisinya maupun 
dalam penggunaan dan perpaduan instrumennya yang lebih besar dibandingkan dengan sebelumnya.

\section{Gaya Bernyanyi Naturalistik pada Musik Populer}

Sebagaimana telah dijelaskan bahwa musik populer mempunyai karakteristik musik yang erat kaitannya dengan bahasa (teks) yang mempunyai gambaran yang kuat secara emosional. Oleh karena itu, peran kata-kata menjadi faktor yang penting terutama ketika sebuah lagu populer dinyanyikan.

As in virtually all song, the role and effect of words are crucial. But the strength of 'naturalistic' tendency is such that a paralinguistic dimension is often as important as direct verbal meanings. Another way of putting this is to say that it is not just what they sing, but the way they sing it that determines what singers mean to us'; 'song words work ... as structures of sound that are direct signs of emotion and marks of character. (Middleton dalam Potter, 2001:28)

Kecenderungan naturalistik pada musik populer mengarah pada gaya 'natural' dalam bernyanyi. Gaya natural dalam bernyanyi ini mengambil bentuk dasarnya dari pengembangan gaya bernyanyi sebelumnya yang berasal dari penggabungan yang saling memengaruhi antar beberapa tradisi musik. Hal ini menyebabkan gaya bernyanyi pada musik populer seperti pada musik rock memiliki karakteristik yang unik yang tidak berusaha menjatuhkan gaya bernyanyi yang ada sebelumnya ataupun untuk bekerja sama dengan gaya tersebut dalam menghasilkan keunikannya. Pendekatan terhadap gaya bernyanyi tersebut dijelaskan oleh Richard Middleton (Potter, 2001: 29) melalui suatu keterkaitan antara tiga unsur musik yang membentuk suatu jalinan yang bersifat 'triangulasi' dan merupakan pertemuan dari berbagai tradisi musik: (1) Terdapat teknik 'natural' yang mengambil bentuknya sebagian besar dari gaya-gaya lagu rakyat baru yang berasal dari Amerika bagian selatan. Gaya tersebut terdapat pada musik country dan di atas semuanya itu blues dan gospel AfricanAmerican. Di samping itu, mengambil pula gaya yang berasal dari sejarah musik populer sebelum kemunculan musik rock yang diakibatkan oleh pengaruh musik jazz; (2) Dari perkembangan yang secara terus-menerus saling memengaruhi, bahkan mungkin lebih menonjol dari silsilah antarmusik tersebut, ditemukan pendekatan-pendekatan yang merupakan turunan dari 'bel canto' (gaya bernyanyi indah dari Italia yang menjadi dasar dari gaya bernyanyi musik klasik Barat). Hal tersebut sebagian besar disebarkan melalui tradisi musicmusik ringan (light music), operet romantik dan balada sentimental yang menyentuh perasaan. Pada tiap pendekatan tersebut, dalam caranya masingmasing, ditemukan dalam suatu konsep 'keaslian'. Konsep yang pertama berdasarkan pada kemurnian emosional dari para penyaji musiknya dan yang kedua pada kemurnian estetik dan teknik yang digunakan; (3) Pada bagian ketiga dari triangulasi tersebut adalah dengan menempatkan konsep keaslian tersebut dalam konteks mengenai teknikteknik pembentukan gaya, berasal dari tradisi teater, cabaret, dan permainan peran bergaya karnaval.

Di sinilah letak perpaduan yang kompleks antara citra dari sang artis, 'gaya penampilan' yang prima dan karakter suara yang mendukung syair bertemu, saling memengaruhi. Di sini pula letak keberadaan sang aktor dalam membawakan lagu dan menampilkan semua karakternya secara lebih berbobot yang didukung dengan bantuan peran media seperti studio rekaman, film, dan video.

Berkaitan dengan peran dan efek dari kata-kata yang dijelaskan oleh Richard Middleton bahwa telah terdapat sebuah penelitian yang menunjukkan para pendengar musik rock memberikan sedikit perhatian pada arti kata secara verbal. Middleton dalam Potter (2001: 29) menjelaskan:

\section{"A more typical situation, perhaps is where a vocal 'hook' works by bundling together the meaning, resonances and sound - shapes of the words together with the melodic, rhythmic, timbral and articulatory dimensions of their sung performance, encapsulating that particular semantic-affective field which will come to be associated with the song".}

Sebagai dampaknya, pada gaya bernyanyi rock terdapat dua kecenderungan ekstrem. Pada salah satu sisi ekstremnya kata-kata menguasai aliran musikal, bekerja sebagai suatu hal yang bersifat 
'naratif'. Produksi suaranya cenderung mengarah seperti orang berbicara. (Salah satu contohnya adalah karya grup musik rock Judas Priest yang berjudul Locked In. Karya ini terdapat pada kaset 'The Very Best of Judas Priest' produksi Team Records tahun 1986 pada side A no. 1). Pada sisi yang lain kata-kata diserap ke dalam aliran musikal, bekerja sebagai 'bunyi' atau 'gesture' (gerak isyarat) yang menyebabkan suara menjadi semacam instrumen. (Salah satu contohnya adalah lagu Gold Mine yang dibawakan oleh grup musik Take 6 pada kaset doo be doo wop bop!, produksi PT. Aquarius Musikindo tahun 1988, pada side A. no 1. Di antara kedua titik ekstrem tersebut, kata-kata muncul bersama dengan melodi menghasilkan 'ekspresi yang dinyanyikan'. Ini adalah sebuah ruang lingkup yang merupakan suatu cabang bersifat klasik dari gaya bernyanyi rock yang membentuk asal-usul lagu-lagu balada. Namun, pendekatan vokal yang lebih 'natural' dapat berkembang pula di sini seperti pada musik-musik soul.

Secara luas dapat dikatakan, anggapan mengenai rock ' $n$ roll berasal dari kemunculan bersama musik country dan rhythm and blues ( $\mathrm{R}$ $\&$ B) adalah benar. Meski nenek moyangnya lebih dominan berasal dari musik kaum kulit hitam, warisan musiknya bergerak melalui kedua jenis musik secara langsung, juga melalui pengaruh musik African - American sebelumnya. Terdapat suatu kesepakatan umum mengenai kecenderungan karakteristik inti dari musiknya, yaitu frase-frase yang pendek, sering bersifat siklus pada bentuknya, biasanya menggunakan tangga nada pentatonik atau modal, namun dengan banyak perubahan artikulasi, lekukan nada, glissando, dan frasenya sering kali diulang. Hubungan antara refren solo dan perulangan oleh anggota di antara penyaji musiknya, aksen yang tidak lazim, sinkopasi dan pemenggalan frase yang fleksibel secara ritmis, varisi register suara yang sangat besar (termasuk penggunaan falsetto) dan variasi timbre atau warna suara termasuk teriakan sorak-sorai, pekikan, geraman, senandung, dan erangan atau rintihan tanpa kata (Middleton dalam Potter, 2001:29).

Karakteristik yang muncul dari berbagai perubahan yang bersifat saling memengaruhi antarberbagai tradisi musik tersebut membuat gaya bernyanyi African-American yang bersifat natural ini memiliki variasi yang luar biasa besarnya. Disebutkan oleh Richard Middleton bahwa gaya bernyanyi tersebut mulai pekikan mengusir yang menyeramkan dari Louis Amstrong hingga geraman yang penuh keagungan dan megah dari Bessie Smith. Sementara itu, produksi suara yang bersifat rileks atau santai secara khusus digunakan dengan jelas pada tingkat kegembiraan yang luar biasa dari gaya bernyanyi gospel yang diedarkan kemudian melalui musik soul dengan tokoh-tokoh pengusungnya, yaitu Mahalia Jackson dan Aretha Franklin.

Suatu gaya bernyanyi natural lain yang bercirikan nada-nada yang tinggi dengan kontrol ketegangan dan nada-nada yang berbunyi sengau dapat dilacak kembali asal usulnya dari musik country di daerah pegunungan Amerika bagian selatan. Meski memiliki pendekatan yang mirip dengan gaya berbicara, jauh lebih tersusun daripada pendekatan African-American yang khas. Sementara itu, gaya ini kemudian sering dimodifikasi sebagai akibat pengaruh gaya bernyanyi kaum kulit hitam. Bersamaan dengan pendekatan tersebut dibawa pula suatu gaya bernyanyi yang menjadi ciri khas musik country, yaitu harmoni vokal terbuka dengan jarak interval kuart dan kuint, tata suara tertutup pada nada-nada yang tinggi dan gerakan paralel. Hal ini dicontohkan oleh kelompok Everly Brothers, Beatles, dan penerus-penerus sesudahnya, pembentukan frase yang sangat konvensional, langkahlangkah ritmis reguler dan dorongan naratif yang mantap terus menerus dari pendongengan balada

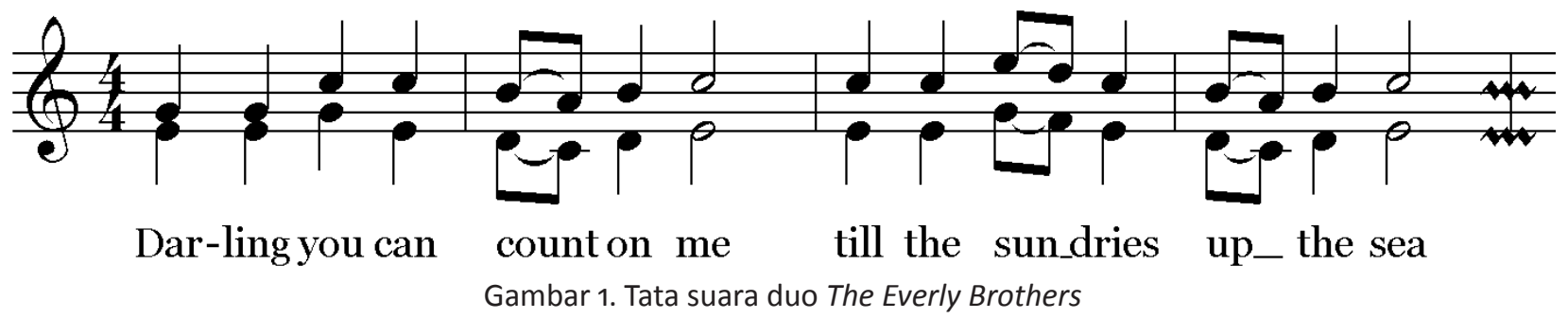


rakyat. (Contoh musiknya dapat didengar melalui lagu Devoted to You yang dibawakan oleh duo The Everly Brothers. Karya tersebut terdapat pada kaset "The Very Best of Everly Brothers" side A. no.1)

Ciri khas yang disebut terakhir mengalir secara jelas melalui lingkungan pergaulan penyanyi dan penulis lagu rakyat. Pengaruhnya kebanyakan didapat melalui suatu silsilah dari Woody Guthrie hingga Bob Dylan yang berusaha keluar dari lingkungan pergaulan para peminat kebangkitan kembali lagu rakyat dan lagu rakyat bernada protes pada awal 1960-an ketika karier Dylan dimulai.

Within the repertoires of country music and $R \& B$ themselves, the occasional assimilation of sentimental pop ballads brought with it an invitation to pursue a more classical singing technique. (Middleton dalam Potter, 2001:31)

Asimilasi tersebut berakar dari lagu dalam negeri pada era akhir Victorian di satu sisi dan Tin Pan Alley yang kontemporer di sisi lain. Hasil asimilasinya menonjol sangat kuat pada beberapa kasus -dari Vernon Dalhart hingga Jim Reeves, dari Lonnie Johnson hingga Johnny Ace - seperti menempatkannya pada batas antara kategori 'ethnic' dan 'mainstream'. Hal tersebut seperti memelihara aturan dari lagu-lagu kaum borjuis abad ke-19 untuk penyesuaian dalam lagu rock. Lebih luas lagi, karya-karya dari artis rekaman klasik awal seperti Enrico Caruso dan penyanyi 'light classic' seperti John Mc Cormack bersama dengan gayagaya yang berkaitan dalam suatu teater musikal Broadway, London dan kota-kota di Eropa lainnya memelihara tradisi tersebut. Sebagai dampaknya di satu sisi terus memberi informasi pada aliran utama gaya bernyanyi populer dan di sisi lain memastikan bahwa perkembangan musik-musik lain termasuk musik rock tidak akan memudarkan popularitasnya. Penemuan alat-alat elektronis termasuk mikrofon ikut memengaruhi bagaimana pengelolaan aspekaspek olah vokal musik klasik digunakan untuk menyanyikan musik tersebut dan menentukan batas-batas penggunaannya.

The coming of the electric microphone enabled crooners from Bing Crosby onwards to approximate the effect without the need for a full-scale trained technique. (Middleton dalam Potter, 2001: 32)

Pada gaya rock ballad, penggunaan ritmis lebih ditekankan untuk menghindari anggapan sebagai musik yang lemah lembut. Pada saat yang sama hal tersebut menunjukkan kesamaan ciri-ciri yang menghubungkan musik Elton John, Barry Manilow, dan Barbra Streisand. Hal tersebut akan sangat membantu dalam memahami bagaimana penyanyi rock kelas berat seperti Meat Loaf dan Freddie Mercury dari kelompok Queen dapat tampil dalam satu panggung bersama dengan Luciano Pavarotti dan Montserrat Caballe secara terhormat.

Berbeda dari musik klasik yang sudah memiliki sistematika yang memadai dalam menilai kualitas kemampuan seseorang dalam bermusik, pada musik populer khususnya dalam menyanyi tidak terdapat suatu kriteria yang lebih jelas selain penguasaan terhadap lagu dan ekspresi sekaligus penampilannya di panggung. Pihak penyelenggara hiburan saat ini tidak kurang strategi untuk bekerja sama dengan berbagai media massa khususnya stasiun televisi untuk menjaring bintang-bintang musik populer baru. Di dunia tarik suara, berbagai ajang kompetisi diselenggarakan dalam bentuk 'reality show'. Dalam acara tersebut ditampilkan perjuangan para peserta yang berusaha menampilkan ekspresi terbaik dalam menjiwai lagu yang dibawakan. Dari sekian macam tahap penilaian yang harus dilalui terdapat suatu tahap ketika para penyanyi yang berkompetisi diberi kesempatan untuk mengolah dan memunculkan karakter suara mereka yang masih terpendam melalui bantuan orang yang sudah berpengalaman di bidang tarik suara. Bantuan dari penyanyi klasik dimungkinkan untuk diberikan dalam tahap ini. Salah satu contoh kejadian tersebut di Indonesia terdapat pada ajang POPSTARS yang ditayangkan oleh stasiun televisi Trans TV sekitar bulan Juni hingga November 2003 yang lalu, salah seorang soprano terkenal Indonesia Binu D. Sukaman memberikan pengarahan pada para peserta untuk menghadapi sesi selanjutnya. Catharina Leimena seorang soprano senior Indonesia mengungkapkan bahwa pada saat ini terjadi peningkatan kesadaran pada penyanyi populer untuk meningkatkan kemampuan olah vokal mereka dalam menghadapi kompetisi olah vokal tersebut. 


\section{Bentuk Penerapan Olah Vokal Klasik Barat pada Musik Populer}

Pada akhirnya tanpa harus kehilangan identitas sebagai musik populer dan sebagai bagian dari teknik bernyanyi yang dikembangkan pada musik klasik Barat, penerapan olah vokal musik klasik Barat pada musik populer mendapatkan peran dan kesempatan yang cukup signifikan dalam ajang kompetisi seperti yang dijelaskan sebelumnya. Kerja sama ini bisa dipahami dari pernyataan Sir Keith Falkner mengenai dua faktor penting yang perlu disadari sebagai seorang penyanyi secara umum sebagai berikut:

Singers have always had two basic things to consider the physical and the aesthetic. They do not change. Alterations in training are only necessary in the applications of technique to current fashions; the principles of fine singing are constant. Indeed they are obvious; but they are not often present together in one person. The voice must have volume, intensity, wide and pleasing quality throughout its range. The breath must be in complete control, unnoticed but in constant support. The attack must be clear and clean... Interpretation should be natural, faithful to composer and poet. (Falkner dalam Falkner, 1994:43)

Berdasarkan pernyataan tersebut akan lebih mudah dipahami bahwa strategi tertentu dibutuhkan untuk menghasilkan sebuah kualitas produksi suara yang ingin dihasilkan oleh seseorang meski dalam konteks musik populer sekalipun. Dalam konteks persaingan yang begitu ketat, sebuah karakteristik unik yang dibina dan dipertahankan khususnya dalam produksi suara akan menjadi suatu nilai tambah yang cukup berarti untuk bisa mengantar seorang penyanyi populer yang baru meniti tangga popularitasnya. Meski teknik olah vokal musik klasik yang diajarkan tidak diterapkan sepenuhnya pada suatu kompetisi olah vokal musik populer, secara praktis semua itu makin memperjelas posisi dan keunikan dari karakter vokal yang dihasilkan dari dan dibutuhkan oleh masing-masing jenis musik.

Edgar Herbert Caesari, seorang ahli olah vokal menjelaskan dalam tulisannya mengenai "The
Science and Sensations of Vocal Tone" bahwa seni menyanyi merupakan sebuah medium bagi manusia untuk menyatakan pikiran dan perasaannya melalui bantuan kata-kata dan nada-nada. Lagu bukan hanya sekadar sarana mengungkapkan ide, melainkan juga sebagai jalan keluar emosional. Penyanyi merupakan media perantara bagi komposer untuk menyatakan pikirannya. Ia tidak hanya mengekspresikan dirinya sendiri melalui lagu yang dibawakannya, namun juga mengekspresikan pemikiran komposer. Untuk itu, salah satu aspek fisik yang perlu diperhatikan penyanyi sebagai pendukung bagi disampaikannya ide-ide tersebut pada berbagai jenis musik secara umum adalah kontrol pernapasan.

In the light of our present knowledge, therefore, the old adage, 'Chi sa respirare sa cantare' (He who knows how to breathe khows how to sing), can profitably reversed: He who sings well breathes well, because the fact of singing well necessarily implies the employment of a good if not perfect vocal mechanism, and the accurate adjustment of the vocal organs at all pitches is in variably and automatically accompanied by adequate and never superfluous breath supply, distribution and expenditure, which in other words, signifies a minimum of breath proportionate to pitch and intensity. (Caesari, 1958:18)

Kontrol pernapasan merupakan dasar dari pembentukan nada dan merupakan bagian dari kerja organ vokal. Hanya ada satu cara untuk bernapas secara benar, yaitu bernapas secara alami. Namun, penyanyi perlu untuk belajar tidak hanya untuk bernapas secara benar, tetapi juga bagaimana mengontrol dan mempergunakan napas seefektif mungkin.

Untuk memahami aspek lain yang tak kalah pentingnya, E.H. Caesari memberikan sebuah analogi bahwa manusia primitif mengekspresikan perasaan gembira mereka dengan meninggikan suara mereka melebihi ketinggian suara biasa mereka ketika berbicara. Hal ini menunjukkan bahwa mereka memakai suatu cara khusus untuk mengekspresikan perasaan tertentu dan hal inilah yang menjadi prinsip bernyanyi. Pemahaman terhadap mekanisme vokal dan interpretasi adalah dua hal yang tak terpisahkan. Interpretasi yang 
tepat tidak akan terjadi tanpa mekanisme vokal yang benar. Apa yang kemudian menjadi dasar fisik dari interpretasi yang tepat adalah adanya teknik vokal. Untuk hal ini Caesari (1958:135) menekankan bahwa: "There can be no singing without technique".

Berkaitan dengan sifat alami dari musik populer, Johan Sundberg menegaskan kembali karakteristik olah vokal musik populer terhadap olah vokal musik klasik sebagai berikut: 'Country singing (and popular singing generally) is more similar to normal speech than classical singing' (Sundberg dalam Potter, 2000:246), Meski demikian, dalam kenyataan terdapat jenis musik populer yang karena asal-usul pembentukannya dimungkinkan untuk menerima penerapan olah vokal klasik yaitu musik yang bergaya R \& B yang berasimilasi dengan musik country. Aspek teknik olah vokal klasik yang mungkin diterapkan kemudian pada jenis musik tersebut di samping kontrol pernapasan yang telah dijelaskan di atas adalah sesuatu yang dipandang sebagai pusat perhatian pada akhir abad ke-19, yaitu "open throat" dan "focus" atau "forward placement". Secara sedehana dapat dijelaskan bahwa open throat adalah terbukanya bagian pangkal tenggorokan dan bagian pangkal lidah yang tetap dipertahankan pada posisi yang rendah sehingga dihasilkan suatu kualitas suara yang jernih. Adapun focus atau penempatan suara ke depan merupakan suatu kualitas produksi suara yang dihasilkan dengan mengarahkan suara tersebut pada tempurung kepala bagian depan. Karena pita suara itu sendiri tidak dapat disentuh dan kinerjanya hanya dapat dirasakan dan didengar melalui bunyi yang dihasilkan maka David Mason memberikan arahan bagaimana karakteristik bunyi yang 'fokus' tersebut dikontrol.

When the singer formant is produced the singer will have the feeling that the voice is forward, or in the mask'. One of the great advocates of singing 'dans le masque' was
Jan de Reszke, who used nasal consonants to help place the sound. (Mason dalam Potter, 2001:215)

Resonansi yang ditimbulkan mampu menghasilkan gema yang merupakan suara yang ditangkap oleh telinga pendengar. Berikut ini terdapat beberapa penerapan olah vokal klasik Barat yang bisa didapati pada musik populer:

\section{Even scale technique (Suara yang bulat rata} sepanjang rentang suara penyanyi)

Terdapat beberapa contoh pembawaan lagu yang mencerminkan karakter penerapan olah vokal di atas. Bahkan dalam beberapa segi mempunyai kemiripan dengan olah vokal klasik yang seperti penyatuan dua register suara: dada dan kepala untuk menyanyikan lagu-lagu dengan jangkauan ambitus suara yang cukup tinggi. Hal ini dapat ditinjau pada pembawaan lagu "A Whole New World" oleh Peabo Bryson dan Regina Belle. (terdapat pada kaset 'Peabo Bryson Super Hits' produksi Columbia Records dan Sony Music Entertainment tahun 2000 pada side A. no 1.) Ketinggian nada ditunjukkan dengan penulisan notasi yang letaknya melebihi garis paranada tertinggi.

Sementara itu, lagu "Love Changes Everything" memiliki karakter pembawaan yang mirip namun dengan suatu klimaks pada nada terakhir yang cukup tinggi untuk dibawakan seorang penyanyi populer pada umumnya. Lagunya dapat didengar pada kaset 'The Very Best of Andrew Llyod Webber', produksi Polydor dan Reality Useful Records tahun 1994, pada side A no.6.

\section{Penggunaan Vibrato}

Salah satu aspek teknis lain dari olah vokal klasik yang diterapkan dan mempunyai suatu jenis perbandingan yang cukup signifikan pada kedua jenis musik vokal klasik dan populer adalah penggunaan vibrato. Johan Sundberg memberikan suatu gambaran perbedaan menda-

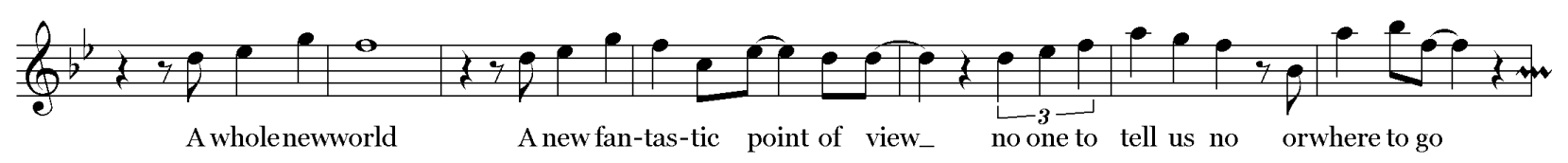

Gambar 2. Potongan Lagu A Whole New World 
sar dari sisi produksi vibrato tersebut oleh organ vokal manusia sebagai berikut:

The vibrato used in classical singing is normally produced by pulsations in the pitch - raising cricothyroid muscle and is a frequency vibrato. In popular music a different kind of vibrato is often used which is generated by variations in subglottal pressure imposing an undulation of voice - source amplitude. It corresponds to an amplitude modulation of the voice source and is really an intensity vibrato. (Sundberg dalam Potter, 2001: 240)

Hasil penelitian mengenai kedua jenis vibrato ini dinyatakan bahwa frequency vibrato sering bersamaan terjadinya dengan modulasi amplitudo dan pengaruh getaran organ vokal ini tidak mudah ditangkap oleh telinga biasa. Namun, satu hal yang dapat dipastikan dalam menghubungkan aplikasi dari kedua jenis vibrato tersebut melalui pernyataan Sundberg sebagai berikut : 'In choral and in pop singing vibrato is typically much smaller than in classical singing. Perbandingan penggunaan vibrato ini dapat dilihat pada lagu bergaya Neapolitan "O Sole Mio" (bentuk partiturnya dapat dilihat pada lampiran no.12) yang dibawakan dalam nuansa populer oleh penyanyi rock n' roll terkenal Elvis Presley. Dengan melodi yang sama, lagu ini diubah syairnya dalam bahasa Inggris dan diganti judulnya menjadi "It's Now or Never". (Contoh lagunya dapat didengar pada kaset 'The Very Best of Elvis Presley' produksi Perina Records tahun 1978 pada side A. no. 1) Meskipun tidak sedramatis seperti pada olah vokal versi klasik, namun tetap dapat dilihat peniruan pembawaan karakter tersebut.

\section{Penggunaan Imajinasi dan Irama yang Bebas}

Aspek yang akan dibahas berikut ini nampaknya berlaku umum dalam setiap jenis musik vokal. Aspek tersebut adalah kemampuan berimajinasi yang sangat menunjang dalam membawakan suatu karya. La Monte Young, salah seorang komposer musik menyatakan pentingnya aspek imajinasi seperti yang diingat oleh Pandit Pran Nath, seorang penyanyi populer berkebangsaan India sebagai berikut : is that you practice it for twenty years, until you can do it in your sleep; then you go on stage and you don't think. You forget everything you know and you just let it happen (Schaeffer dalam Potter, 2001:11). Di India sendiri hal ini dinamakan uppaj yang berarti imajinasi atau terbang seperti burung. Pernyataan senada diungkapkan pula oleh Dame Janet Baker sebagai seorang ahli olah vokal klasik Barat sebagai berikut:

...Suppose the work speaks of situation, or an emotion which is right outside my own direct experience? I must rely then on imaginative ability, something without which no singer can survive... It is very important to memorize plenty of time even more important to give the words and music a chance to settle into the depths of mind. (Baker dalam Falkner, 1994:90, 92)

Menurutnya, semua itu perlu dilakukan oleh para penyanyi pada masa kini sebagai seorang yang berdedikasi penuh bukan hanya demi suatu pencapaian ketenaran dan keuntungan meski keduanya juga perlu diupayakan. Penggunaan imajinasi tersebut dapat ditinjau melalui lagu "Monalisa" yang dibawakan oleh penyanyi Rhythm n Blues tahun 1960-an, yaitu Nat King Cole. (Bentuk partiturnya dapat dilihat pada lampiran no.12 dan lagunya dapat didengar dari kaset 'The Best of Nat King Cole' produksi Contessa Records pada side A. no. 9) Lagu ini mengambil inspirasi dari lukisan Monalisa karya Leonardo da Vinci. Gaya menyanyinya menunjukkan pengolahan ritmis yang lebih bebas dan musik yang mengikuti alur syair seperti penggarapan komposisi yang mirip bentuk "through composed". Lebih jauh daripada itu karena penyanyi adalah pelayan setia bagi musik, komposer dan publik.

\section{Penggunaan Hiasan Nada (Ornamentasi)}

Olah vokal lain yang dapat diterapkan pada musik populer adalah penggunaan ornamentasi. Pada beberapa jenis musik seperti $\mathrm{R} \& \mathrm{~B}$, ornamentasi tersebut mendapatkan perhatian yang lebih besar dalam penggunaannya. Salah satu contoh yang menarik adalah penerapan portamento pada lompatan oktaf yang terdapat 


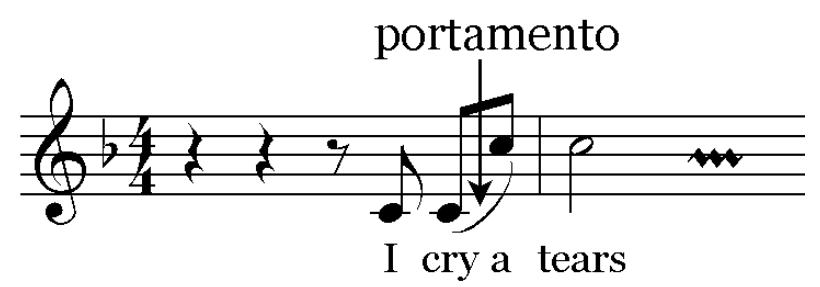

Gambar 3. Potongan awal lagu You Needed Me dengan portamento

pada awal lagu "You Needed Me" yang dibawakan penyanyi Anne Murray. Lagu ini dapat didengar melalui kaset 'Beautiful Love Songs vol. 2 yang diproduksi oleh EMI Malaysia tahun 1993 pada side B. no 4 .

Penggunaan sinkop yang menjadi ciri khas dari musik populer terdengar cukup jelas pada bagian awal lagunya. Sementara itu, Whitney Houston dalam lagu "I Will Always Love You" membawakan suatu gaya menyanyi yang dekat dengan gaya recitative dan aria. Penggarapan recitative-nya sangat bernuansa populer karena tetap menggunakan lagu tema, hanya dibawakan tanpa iringan dengan ritmis yang lebih bebas dan penuh dengan ornamentasi yang berupa glissando dan lekukan-lekukan nada. Pada bagian akhir dari lagu ini bahkan meniru konsep aria (bagian solo dari suatu opera pada musik klasik Barat) dengan suatu pembawaan yang mirip cadenza (bagian lagu yang memperlihatkan unjuk kebolehan penyanyi dalam membunyikan nada-nada dengan teknik yang cukup sulit), meski tidak mengunakan unsur-unsur olah vokal dramatis. Lagunya dapat didengar pada kaset 'The Greatest Hits of Whitney Houston - Cooling Down' produksi PT Arista Records pada side A. no. 5)

\section{Gaya Bernyanyi Gregorian sebagai Aspek Kebaruan}

Isi dan jangkauan musik pop diperluas oleh usaha para musisi itu sendiri seperti menggali aspek-aspek musik yang bernuansa logat asli dari daerah-daerah di luar negara mereka. Penemuan berbagai peralatan elektronik pendukung seperti synthesizer mampu memberikan nuansa yang nampaknya 'baru' dalam penggarapan musiknya. Aspek kebaruan dalam musik mereka yang diungkapkan oleh Dieter Mack berikut ini juga mempunyai dampak terhadap bagaimana orang menanggapi kehadiran suatu penggarapan musik populer.

Tampaknya manusia kini tidak terbiasa lagi dengan keperluan konsentrasi yang lebih lama. Hal ini terbukti justru dalam bidang musik populer dengan karya karya yang rata-rata hanya berbunyi selama 2 sampai 3 menit. Tidak penting bila karya tersebut kurang lebih sama esensinya, dibandingkan dengan yang sebelumnya, asal terdapat bayangan - "ada sesuatu yang baru"- Untuk fungsi tertentu ini gramatik musiknya tidak boleh keluar dari unsur-unsur yang telah dianggap sesuai dengan kebiasaan musik pada umumnya. (Mack. 1995:128)

Perkembangan bisnis rekaman musik membawa pada tuntutan performa yang lebih besar pada para pelakunya. Perusahaan rekaman berusaha memuaskan para penyandang dana mereka dan institusi tersebut bukan sebuah badan amal. Pem-buatan rekaman membutuhkan biaya yang sangat mahal. Perannya dalam melayani publik penggemar musik dan pemenuhan kebutuhan bagi program siaran melalui media massa secara komersial menyebabkan kesempatan kerja bagi para musisi tidak bisa ikut meningkat begitu saja. Hal ini berkaitan dengan peningkatan jumlah publik yang menikmati pertunjukan serta karya-karya mereka melalui rekaman.

The record industry also responds to the market. Popular works that sell well will naturally be more attractive than works that have a small sale. This makes it difficult to get new or unfamiliar works recorded, though there are one or two smaller companies who specialize in works off the beaten track. (Tschaikov dalam Spence \& Swayne, 342)

Pada akhirnya demi mendongkrak penjualan rekamannya, perusahaan tersebut mempekerjakan artis-artis yang sudah mempunyai nama. Sangat penting bagi perusahaan tersebut untuk menggunakan artis-artis yang telah mempunyai kaitan atau citra dengan suatu ciri 
musik tertentu, juga jenis-jenis repertoar yang dibawakan dengan instrumen musiknya dan pengolahannya yang dapat dengan segera dikenal oleh masyarakat luas. Sejumlah besar uang dikeluarkan untuk mempublikasikan artis tersebut karena merekalah yang ingin publik dengar, lihat dan nikmati dari musik dan penampilannya terutama melalui rekaman. Mereka menjadi sangat mahal dan dalam beberapa segi merupakan aset berharga dan bernilai seperti sebuah perhiasan yang mahal dan langka. Bagi para pendatang baru hal ini menjadi sulit khususnya untuk meraih posisi seperti para pendahulunya baik dari sisi pendapatan maupun publisitas.

More performer mean higher standards; while the public responds to familiarity and listens to reproduced performances made by a relatively small number of performers in orchestras and groups fortunate enough to obtain recording contracts. (Tschaikov dalam Spence \& Swayne, 343)

Dalam hal ini aspek kebaruan yang dituntut dalam penggarapan musik populer bahkan telah memasukkan karakter suara gregorian seperti apa adanya. Hal ini dapat didengarkan pada lagu "In The Air Tonight" yang telah populer dibawakan oleh penyanyi Phil Collins. Perbedaan yang signifikan hanyalah pada dukungan ritmis yang reguler dalam lagunya. Lagu tersebut dapat didengar pada kaset 'Gregorian Master of Chant Chapter II’ produksi Edel Media \& Entertainment GmbH tahun 2001.

Dari semua aspek yang telah dikemukakan di atas, Sergius Kagen memberikan suatu kesimpulan terhadap apa yang bisa diperbuat oleh seorang penyanyi terkait dengan tujuannya dalam mengolah kualitas suaranya.

Singing for pleasure requires only the desire. Singing for other people's pleasure demands certain standards of excellence. Singing for professional standards requires an excellence comparable to the best singers of the day. (Falkner dalam Falkner [ed.], 1994:42)

Dengan demikian, penerapan olah vokal klasik pada musik populer mampu memberikan sumbangan yang berarti pada perkembangan musik populer sejauh karakter-karakter dari masing-masing musik diperhatikan dengan saksama, sehingga tidak menimbulkan suatu yang berkesan campur tangan yang tidak perlu.

\section{Simpulan}

Musik klasik Barat mempunyai keterkaitan yang cukup besar dalam pengembangan musik populer khususnya pada musik vokal karena bentuk instrumen musik ini relatif tidak berubah bentuknya dari zaman ke zaman. Perubahan terjadi dalam kerangka pemikiran bentuk-bentuk musik yang muncul karena pengolahannya, karena itu dapat ditinjau pula penerapan olah vokal klasik pada musik populer dari sudut pandang aspekaspek metode olah vokal yang telah dikembangkan dalam musik klasik. Aspek-aspek tersebut seperti: pengolahan napas, resonansi, artikulasi, penggunaan ornamentasi, dan produksi suara secara keseluruhan, namun dengan tidak meninggalkan karakteristik umum yang dimiliki oleh kedua jenis musik tersebut.

Di samping tinjauan berbagai konteks penerapan tersebut perlu juga dilihat efektivitasnya seperti dalam kerangka kompetisi olah vokal musik populer ataupun dalam jenis-jenis musik populer yang dibawakan. Hal ini mengingat pada asal usul musiknya, aspek-aspek yang dapat diterapkan serta dampak yang ditimbulkan terhadap perubahan karakter pembawaan musiknya. Dengan kata lain, musik populer tidak perlu berkesan menjadi seperti musik klasik hanya karena penerapan aspek-aspek olah vokal klasik diberikan tanpa mempertimbangkan sifat alami dari musik populer itu sendiri.

\section{Ucapan Terima Kasih}

Ucapan terima kasih disampaikan kepada Prof. Dr. Victor Ganap, M.Ed. atas segala bimbingan dan masukan pada saat penyusunan artikel ini dan UPT Perpustakaan Institut Seni Indonesia Yogyakarta yang telah menyediakan berbagai bahan bacaan yang sangat membantu dalam proses penulisan. 


\section{Kepustakaan}

\section{Buku}

Caesari, Edgar Herbert. 1958. The Science and Sensations of Vocal Tone. UK: J.M. Dent

Mack, Dieter. 1995. Apresiasi Musik Populer. Yogyakarta: Yayasan Pustaka Nusatama.

Pasaribu, Amir. 1997. Ensiklopedi Musik. Jakarta: PT Delta Pamungkas.

Ribeiro, Victor Rangel. 1981. Baroque Music. USA: Schirmer Books

Sumaryo, L.E. 1978. Komponis, Pemain Musik dan Publik. Jakarta: PT Dunia Pustaka Jaya.

\section{Bunga Rampai}

Baker, Dame Janet. 1994. "The Life of a Singer Today" dalam Sir Keith Falkner (ed.). Voice. UK: Kahn \& Averill Ltd.

Bowen, Meirion. 1981. "The Potential of Pop" dalam Keith Spence \& Giles Swayne (eds). How Music Works. USA: Macmillan Publishing Co

Falkner, Sir Keith. 1994. "Ancestral Voices" dalam Sir Keith Falkner (ed.). Voice. UK: Kahn \& Averill Ltd.

1994. "Training: the Singer as Technician” dalam Sir Keith Falkner (ed.). Voice. UK: Kahn \& Averill Ltd.

Jender, Owen. 1980. "Singing, Early History" dalam Stanley Sadie (ed.). The New Grove Dictionary of Music and Musicians vol. XVII. UK: Macmillan Publisher Limited.

Mason, David, 2001. "The Teaching (and Learning) of Singing" dalam John Potter (ed). The Cambridge Companion to Singing. UK: Cambridge University Press.

Middleton, Richard. 2001. "Rock Singing" dalam
John Potter (ed). The Cambridge Companion to Singing. UK: Cambridge University Press. Schaefer, John. 2001. "Songlines: Vocal Traditions in World Music" dalam John Potter (ed). The Cambridge Companion to Singing. UK: Cambridge University Press.

Shadily, Hasan (et al). 1984. Ensiklopedi Indonesia jilid VII. Jakarta: Ichtiar Baru - Van Hoeve.

Sundberg, Johan. 2001. "Where Does the Sound Come from?" dalam John Potter (ed). The Cambridge Companion to Singing. UK: Cambridge University Press.

\section{Surat Kabar}

Tim Redaksi Kompas. 2004. Suara Bergairah Norah Jones, Kompas, Minggu, 18 Januari, hlm.1 \& hlm. 11

\section{Audio (Pita Kaset)}

Brothers, Everly. 1978. The Very Best of Everly Brothers. Contessa Records.

Bryson, Peabo. 2000. Peabo Bryson Super Hits. Columbia Records dan Sony Music Entertainment.

Houston, Whitney. 1998. The Greatest Hits of Whitney Houston - Cooling Down. PT. Arista Records.

Master of Chant, Gregorian. 2001. Gregorian Master of Chant Chapter II. Edel Media \& Entertainment $\mathrm{GmbH}$.

Priest, Judas. 1986. The Very Best of Judas Priest. Team Records.

Take 6. 1988. Doo be doo wop bop! PT Aquarius Musikindo.

Webber, Andrew Llyod. 1994. The Very Best of Andrew Llyod Webber. Polydor dan Reality Useful Records. 